\title{
Genes, modules and the evolution of cave fish
}

\author{
H Wilkens \\ University of Hamburg, Biozentrum Grindel und Zoologisches Museum, Hamburg, Germany
}

\begin{abstract}
Cave fish provide a model system for exploring the genetic basis of regressive evolution. A proposal that regressive evolution (for example, eye loss) may result from pleiotropy, by selection on constructive traits (for example, improved taste) has received considerable recent interest as it contradicts the theory that regressive evolution results from neutral evolution. In this study, these theories are reviewed by placing the classical and molecular genetic studies of cave fish in a common framework. Sequence data and the wide range of intermediate sized eyes in hybrids between surface and cave fish suggest that currently there is no strong evidence supporting the notion that structural eye genes have been afflicted by destructive mutations. The hedgehog genes, which are suggested to reduce the primordial eye cup size in cavefish by expanded expression, are also not mutated. The as yet unidentified 'eye genes' revealed by
\end{abstract}

Keywords: Astyanax; eye regression; hedgehog; mutation pressure

crossing experiments seem primarily responsible for eye regression and determine eye development through hedgehog. Hybrids between different eye-reduced cave populations developing large 'back to surface eyes' support this. In such eyes, $h$ h expression is restored by complementary restitution because of the recombination of 'eye genes', which were subjected to different destructive mutations in separately evolving cave fish populations. All regressive and constructive cave fish traits can be considered to result from genetic modules, each showing a comparable pattern of expression. The constructive and regressive modules are shown to inherit independently from each other, which does not support the view that eye regression is a spin off effect of the improvement of beneficial traits through pleiotropy. Heredity (2010) 105, 413-422; doi:10.1038/hdy.2009.184; published online 13 January 2010

\section{Introduction}

Cave living animals have originated in the most diverse systematic groups and deliver outstanding examples of the convergent loss of traits that have become biologically useless, and the simultaneous constructive improvement of traits that enable their survival in continuous darkness. The neotropical characid fish Astyanax fasciatus (Cuvier 1819) (syn. A. mexicanus Filippi), which has developed a series of cave living populations within a restricted area in Northeastern Mexico, has become a model species in evolutionary research (Mitchell et al., 1977; Jeffery, 2001; Wilkens, 1988, 2004). The cave forms are characterised by the regressive evolution of all traits of which biological function is dependant on the presence of light; such as the eyes (Wilkens, 1988), the number of melanophores (Wilkens, 1988), the melanin pigmentation (Sadoğlu, 1955, 1957; Sadoğlu and McKee, 1969), the dorsal light reaction (Langecker, 1993) and the visually triggered aggressive behaviour (Hofmann and Hausberg, 1993). Traits that were constructively improved as adaptations to cave life include the number of taste buds (Schemmel, 1974), the angle of feeding on the ground (Schemmel, 1980), the ability of fat storage (Hueppop, 1989), the egg size (Hueppop and Wilkens, 1991), the number of free

Correspondence: $\mathrm{Dr} H$ Wilkens, University of Hamburg, Biozentrum Grindel und Zoologisches Museum, Martin-Luther-King-Platz 3, Hamburg 20146, Germany.

E-mail: Wilkens@uni-hamburg.de

Received 26 July 2009; revised 19 November 2009; accepted 3 December 2009; published online 13 January 2010 neuromasts of the lateral line sense (Wilkens unpublished), and aggressive behaviour as triggered by the lateral line sense (Hofmann and Hausberg, 1993).

The Astyanax model delivers an extraordinary experimental tool to study the evolution of cave animals. It is possible to perform comparative studies of the specific evolving morphological, physiological and behavioural features in the closely related surface and cave forms and, of even greater importance, the interfertile surface and cave forms can still be hybridised. From their crosses, conclusions on the genetic basis and phenotypic manifestation of traits can be drawn (Wilkens, 1988). To date, the research of Astyanax cave fish has mainly focussed on two objectives: (1) To analyse the genetic basis of regressive evolution. This objective has most intensively been studied using the cave fish eye phenotype, with studies aiming to elucidate, which and how many genes are responsible for eye regression and whether or not these genes were subjected to destructive mutations. (2) To analyse the evolutionary processes that lead to constructive (for example, enhanced number of taste buds improving food finding ability in darkness) and regressive (for example, loss of eyes) evolution of cave phenotypes. Although it is generally accepted that traits, which are important for living under the specific biotic cave conditions evolve constructively under the influence of selection, there has been much debate over whether regressive evolution is influenced by positive selection or through processes such as mutation/genetic drift, in which destructive mutations are not eliminated (Culver and Wilkens, 2000; Wilkens, 2004, 2007; Jeffery, 2005). In the latter hypothesis, mutation pressure leads to an intermediate phase of variability, until functionless 
traits become rudimentary and finally completely disappear (Kosswig, 1940, 1949, 1959; Wilkens, 1988). Several hypotheses have been suggested for the role of selection in eye regression. In addition to the hypothesis that an exposed eye may be a deleterious risk in darkness (Barr, 1968; Strickler et al., 2007), it has recently been suggested that the same genes, which are responsible for eye or pigment regression, would simultaneously improve specific constructive traits. Thus, selection would indirectly influence the reduction of the eye by pleiotropy through a constructive trait such as taste or energy economy (Barr, 1968; Jeffery, 2005; Protas et al., 2007).

A series of recent studies have provided insight into the developmental mechanisms of eye loss in cave fish, suggesting a central key role of the lens in eye and, in particular, retina development (Jeffery et al., 2003; Jeffery, 2005). However, this finding was shown to be in contrast with former results of classical genetic crossing experiments and histological observations, which revealed that the lens inherits independently from most other structures of the eye and in particular does not influence the development of the retina (Wilkens, 1988, 2007). In this study I put, for the first time, the results of classical genetics and those of developmental evolutionary genetics together in a common frame work.

Franz-Odendaal and Hall (2006) have argued that one can consider cave fish traits such as the eye or taste buds as modules, each of which have their own unique sets of cells, genetic networks and processes. By showing that classical and molecular genetic principles of inheritance found for the cave fish eye can also be transferred to other regressive traits or modules such as pigmentation and even to constructive ones such as taste buds, I also shall contribute to the genetic basis of modularity.

\section{Genetics of complex regressive and constructive traits as revealed by crossing experiments}

The regressive eyes of the most strongly reduced Astyanax cave fish are sunk into the interior of the orbital cavity, overgrown by epidermal tissue and no longer externally visible. The visual cell layers (outer plexiform, outer nuclear layers and visual cell outer segments), as well as the lens, are absent in the adult cave fish. In contrast, in cave fish the sense of taste is improved by enhancement of the number of taste buds, which cover larger areas on the upper and lower jaws compared with surface fish (Wilkens, 1988).

Although being regressive on the one hand and constructive on the other, remarkable congruence between the inheritance of eye size and number of taste buds can be observed. In the F2-cross between surface and cave fish the distributions of both traits (eye size and taste bud number) range between the parental forms and are normally distributed with intermediate means (Figure 1). The means of both traits are also intermediate in the F1-cross, but the distribution curve for each trait shows a smaller variance than that found in the F2-cross. The distribution of eye size and taste bud number in the backcrosses between the F1-specimens and the surface or cave fish ranges between the F1 and the surface or cave fish, respectively. There is a difference in the distribution curves of each trait, however, depending on the size of the traits in the parental generation. For backcrosses between F1 specimens and the cave fish, which has a reduced eye, and between F1-specimens and the surface fish, which has only a few taste buds, distribution curves are normally distributed. However, a second peak (bimodality in eyes) or skewness (taste buds) of the distribution curves occurs in the backcrosses of F1 specimens and the parental surface fish with large eyes or cave fish with high taste bud numbers. This second peak or the skewness is interpreted as being caused by an unproportional increase of phenotypic manifestation. This increase is not due to monofactorial inheritance, because at least eight eye polygenes were calculated to be responsible for the eye size difference between cave and surface fish (Lande, 1981; Wilkens, 1988; Culver and Wilkens, 2000; Protas et al., 2007). Multiple polygeny is also found in other complex regressive and constructive cave fish traits and the false assumption of apparent monofactorial inheritance was studied in detail for feeding behaviour (Schemmel, 1980).

In all the different crossings (F1, F2 and backcrosses) all possible intermediate stages of eye sizes or numbers of taste buds between cave and surface fish develop. Hybrids with eyes of intermediate sizes and intermediate numbers of taste buds are the most common, whereas those similar to the parental forms are rare. However, independent of the range of eye sizes, all hybrids contain the characteristic single structures such as eye lenses or retinas, the size of which correlate with that of the whole eye. No genes specific for certain structures such as lens, retina or pigment epithelium could be distinguished in crossing experiments. Using this method, it was only possible to analyse genes, which were quantitative in character and are responsible for eye size or taste bud number as a whole.

The comparison of the results of crossing experiments involving eye and taste bud traits with those of crossing experiments of other complex polygenic traits, such as the numbers of melanophores and neuromasts or fat storage ability, shows that independently from being regressive or constructive, behavioural, physiological or morphological, all traits in principle are characterised by the same patterns of phenotypic manifestation (Wilkens, 1988, 2004).

\section{Developmental genetics and histology of the cave fish eye during ontogeny}

Comparative measurements of eye size and body length during ontogeny revealed that the surface fish eye grows in a more or less continuously isometric manner. In contrast to this, the ontogenetic eye size development of cave fish is divided into three major developmental steps during which a process of ontogenetic regression takes place (Wilkens, 2007). Each of these steps contributes to regression and diminution of eye size, whereas in interconnecting linear growth phases the eye still increases in size but to a lesser extent than in surface fish (Figure 2): (1) The first step is characterised by the development of primordial eyes that are smaller than in the surface fish. (2) During the second step the cave fish eye either stops growing or declines in size, depending on the specific size of the primordial eye. The primordial 

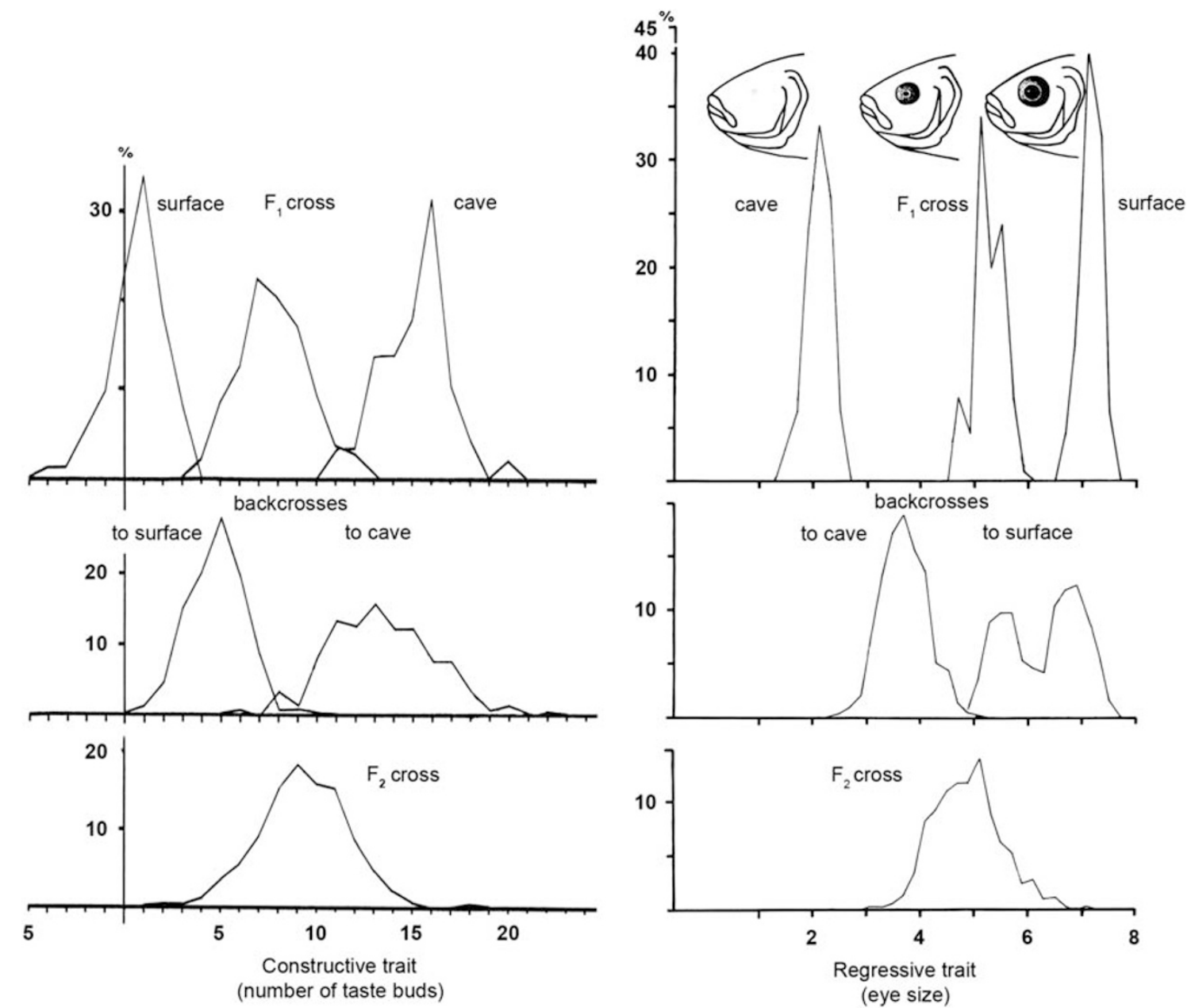

Figure 1 Distribution of taste bud number and eye size in the Astyanax surface and cave population and their crossings (from Wilkens, 1988; Schemmel, 1967).

eye size varies between the different cave populations of Astyanax fasciatus being larger in the Pachón and Molino caves. For the Pachón population, there is evidence from microsatellite and mitochondrial DNA studies that introgression from surface populations has occurred, which is also suggested for other cave populations such as Molino (Strecker et al., 2003, 2004). It is, therefore, possible that the larger primordial eyes are due to introgression of surface eye genes, which may have reversed and temporarily delayed the regressive process (Wilkens, 2007). (3) In the third step, the final state of eye regression is achieved showing the typically increased variability in size and structures of the adult cave fish eye. It seems to develop after the eye has finished the induction of the head skeleton (Mathers and Jamrich, 2000).

It was shown that sonic hedgehog (shh) and tiggy-winkle hedgehog (twhh) gene expression is expanded along the anterior embryonic midline in several different cave fish populations (Yamamoto et al., 2004). The expansion of $h h$ signalling is thought to result in hyperactivation of downstream genes and arrested eye growth and development. These features can be pheno-copied in surface fish by overexpression of twhh and/or shh, supporting a role for $h$ h signalling in cave fish eye regression (Yamamoto et al., 2004; Jeffery, 2005). These studies suggest that the formation of the smaller primordial eye cup in the cave fish is caused by expanded hh expression, which occurs during the above described first step of eye development. At this stage, the smaller primordial eye cup in the cave fish also induces a smaller lens placode (Figure 3, step 1). As there is a continuous distribution curve of eye sizes in the hybrids between surface and cave fish (Figure 1) I suggest that the varying eye sizes of these hybrids may result from variation in $h h$ expression.

Although during this first step of eye regression the size of the lens placode closely correlates with eye cup size as is a characteristic of vertebrates, the subsequent second and third step of eye regression seem to be characterised by the independence of lens and retina differentiation (steps 2 and 3 in Figure 3). This independence is suggested by histological studies of larval and adult hybrids, which revealed that the lens size correlates with that of the anterior eye chamber and the cornea, and in the same way the size and degree of differentiation of the retinal layers correlate with that of visual cell outer segments, pigment epithelium, optic nerve and lens muscle (Wilkens, 1988). The existence of two independent developmental units within the eye could also be deduced from the finding of large lenses combined with undifferentiated retinas or of welldeveloped retinas combined with rudimentary lenses in 


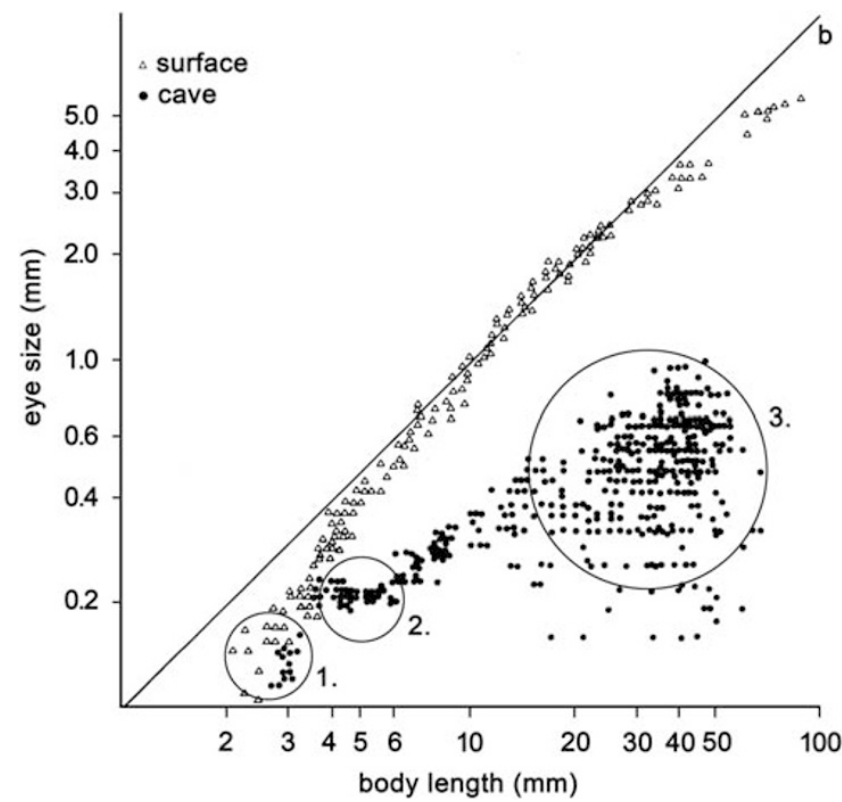

Figure 2 Ontogenetic growth curve (double logarithmic) of the eye of the Astyanax surface and cave populations. Each symbol indicates eye size (measured as eye diameter) and body length (measured as standard length) of one specimen, $b=$ line of isometric growth of the eye, circles 1 to 3 indicate the three major steps of eye reduction during ontogeny (from Wilkens, 2007).

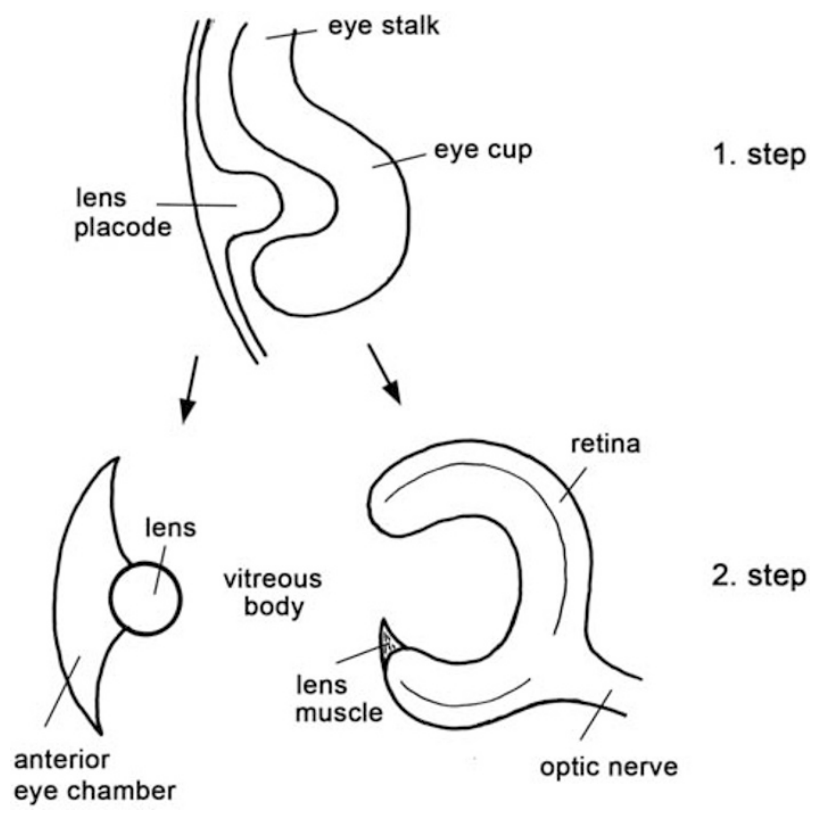

Figure 3 Scheme of the ontogenetically early first and second step of eye reduction (steps 1 and 2 correlate to circles 1 and 2 in Figure 2).

larval and adult hybrids (Wilkens, 1988, 2007). However, proper development of both subunits is required to enable development of the vitreous body: in some specimens, in which eyes contain a rudimentary lens without a crystalline nucleus in combination with a welldeveloped retina, the retina may get undulated or grow into the choroid along the falciform process. The latter occurs because the lens is failing to co-induce a vitreous body of sufficient size to induce an eye ball large enough for the retina. In other specimens, the existence of a large lens may overstretch and tear a too small retina (Figure 4).

The developmental independence of the lens and retina is also shown by histological analysis of cave fish from the Molino cave; whereas in all other cave fish, such as those from Pachón and Sabinos populations, no visual cell outer segments develop during any ontogenetic stage, study of juvenile stages of the Molino population revealed that well-layered rod and cone outer segments are transitorily formed, although the lenses do not differentiate better than in all other cave populations (Figure 5) (Wilkens, 2007).

By the transplantation of an embryonic surface fish lens into a cave fish larval eye the anterior eye chamber and the pupil were restored, which externally provided the impression of a restored eye (Yamamoto and Jeffery, 2000; Jeffery, 2005; Alunni et al., 2007; Strickler et al., 2007). This result is in accordance with the finding of an independent developmental unit induced by the lens and consisting of lens, anterior eye chamber and cornea. However, histological proof of the recovery of parts of the second developmental unit within the eye, (that is, retina including visual cell outer segments and lens muscle), was not provided by the lens transplantation experiment (Yamamoto and Jeffery, 2000; Jeffery, 2005). Rather, it was suggested that the detection of 'a small number of cells expressing rhodopsin in the cave fish retina' indicated that the retina had been restored (Yamamoto and Jeffery, 2000). This finding is not sufficient proof of the recovery of the retina, because expression of an opsin gene was also found in cave fish, containing strongly reduced retinas, from the Piedras population (Langecker et al., 1993). Therefore, it is likely that in cave fish with a transplanted lens from surface fish the retina remained in its reduced state characteristic of other cave fish. This result is supported by the observation that these specimens did not respond to light (Romero et al., 2003). This finding suggests that for the restoration of an eye two subunits, lens and retina, would be necessary. Thus the 'complete restoration of the

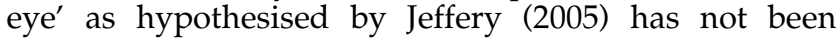
shown and hence there is no support for the hypothesis that the lens alone has a 'central role in cave fish eye development'.

\section{Eye genetics}

Gene expression and sequencing data of cave fish showed that destructive loss-of-function mutations have probably not occurred in cave fish eye genes, including those structural genes that function at the bottom of the regulatory cascades (Jeffery, 2005). In addition, mapping of candidate genes shh, twhh and Pax6 revealed that no eye quantitative trait loci (QTLs) are located near these loci. This result makes it unlikely that mutations in any of these genes are directly responsible for eye regression (Protas et al., 2007). This finding is also supported by the observation that all the different-sized eyes developed in hybrids between cave and surface forms show all the structures characteristic of an eye such as lens, lens muscle, pupil and retinal layers (Wilkens, 1988, 2007). Only the size of these structures varies in correlation with overall eye size. This observation furthermore 
a

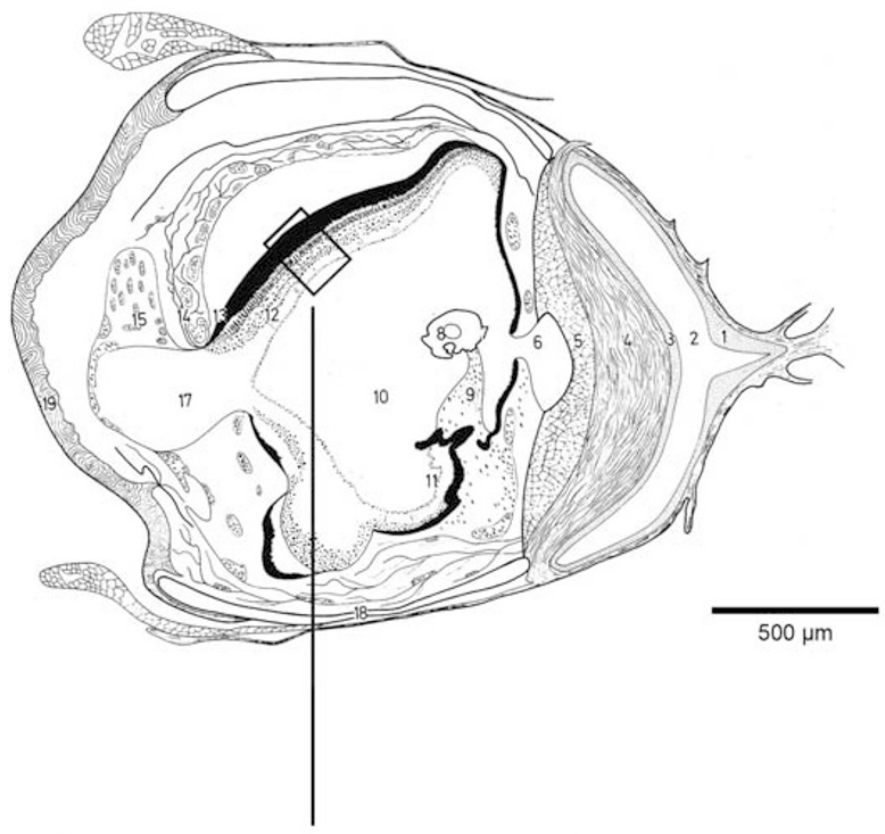

b
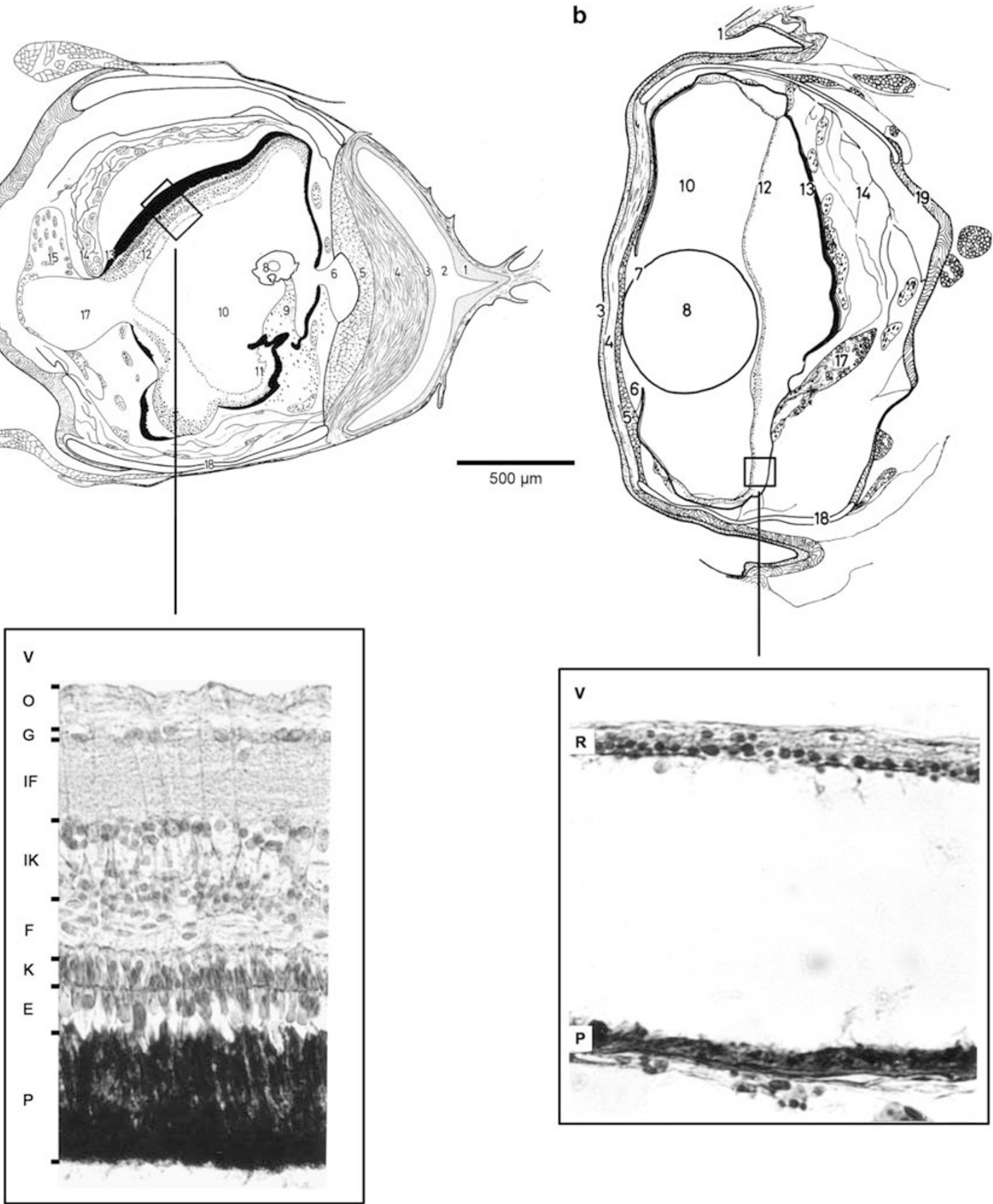

Figure 4 Histological transverse sections of variable eyes: (a) large lens combined with unlayered retina rudiment, (b) lens rudiment combined with fully layered retina (from Wilkens, 1972). 1, epidermis; 2, drawdown duct; 3, cornea conjunctiva; 4, cornea propria; 5, ligamentum annulare; 6, anterior eye chamber; 7, lens capsule; 8, lens crystalline nucleus; 9, lens muscle; 10, vitreous body; 11, falciform process; 12, retina; 13, pigment epithelium; 14, choroid; 15, choroid gland; 17, optic nerve; 18 and 19, sclera; E, visual cells; F, outer plexiform layer; G, ganglion layer; IF, inner plexiform layer; IK, inner nuclear layer; $\mathrm{K}$, outer nuclear layer; $\mathrm{O}$, optic nerve fibres; $\mathrm{P}$, pigment epithelium; $\mathrm{V}$, vitreous body.

shows that the genes involved in eye development can potentially be expressed. For example, a red-like opsin gene is transitorily transcribed in Piedras cave fish during early ontogeny (Langecker et al., 1993). In addition, the $\alpha \mathrm{A}$-crystallin gene, which is responsible for the development of a proper lens in surface fish, shows no destructive mutations, but is never activated in cave fish (Behrens et al., 1998). Even the Pax6 gene shows no destructive mutations (Behrens et al., 1997; Strickler et al., 2001). Thus, I suggest that eye regression in Astyanax seems to be mainly because of downregulation of structural genes by the expanded $h h$ gene expression, which was suggested to have a causal role in eye development of the cave fish (Yamamoto et al., 2004). However, the question of what causes downregulation of hh genes remains unsolved.

Deeper insight into eye genetics can be derived from crossings between different cave populations; whereas hybrids between surface and cave populations contain eyes of all possible intermediate sizes between the parental forms, the crossings between different cave fish populations deviate from this and may very often 
develop slightly larger and better differentiated eyes than the parental cave fish eye rudiments. Usually, rudimentary lenses may occur in adult hybrids (Wilkens, 1988, 2007). An exceptional situation is found in the

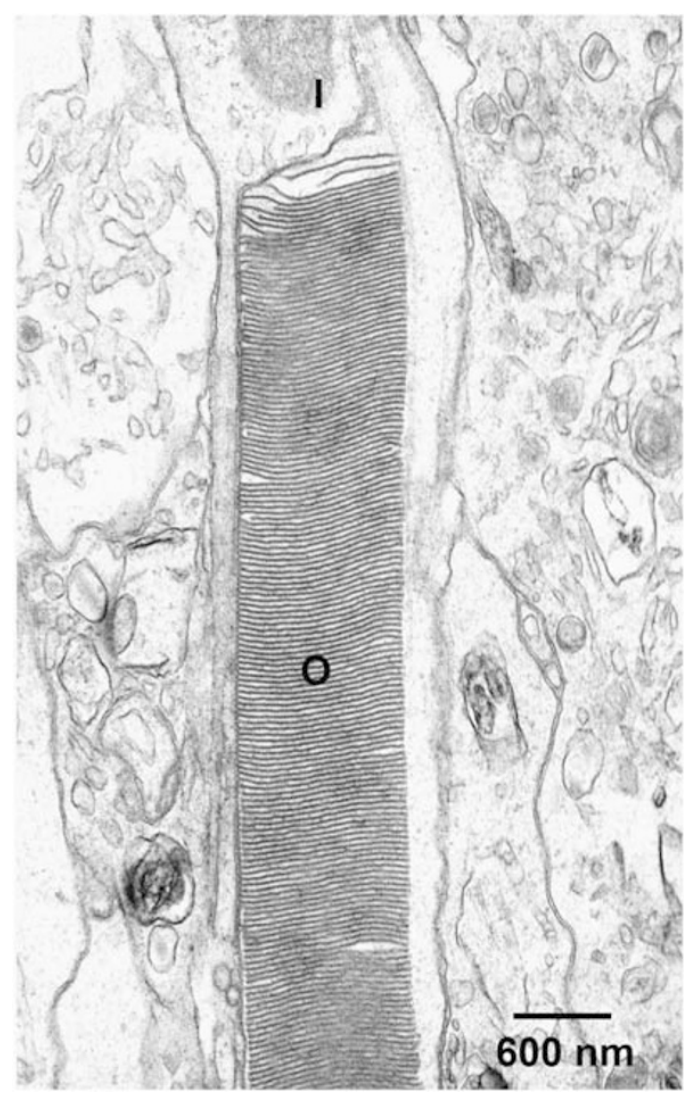

Figure 5 Ultrathin section of a rod visual cell outer segment of juvenile Molino cave fish retina ( $\mathrm{I}$, inner segment; $\mathrm{O}$, outer segment with discs).
F2-cross between the Pachón and the Molino cave fish populations, in which 'back to surface eyes' develop. Among a large number of specimens with small eyes that as in the parental forms and in their F1-cross are sunken into the orbital cavity, several of the adult specimens have externally visible eyes with wide pupils. Histological sections of the eyes from these latter specimens show the presence of large transparent crystalline lenses as well as retinas containing all optical layers with morphologically intact visual cells including pigment epithelium, optic nerve and lens muscle (Figure 6) (Wilkens and Strecker, 2003).

Keeping in mind that expanded expression of the $h h$ genes may have a causal role in eye reduction of the parental cave fish, the development of 'back to surface eyes' could be explained by the secondary restriction of expression and downregulation of $h$ h genes. I suggest that this could be due to as yet unidentified genes. In contrast to the $h h$ genes, it is likely that these genes show loss-of-function mutations. In 'back to surface eyes' they could be expressed again because of the complementary restitution of their function. The complementary restitution then would be brought about by the recombination of different loss-of-function genes in F2 cross hybrids, which derive from different geographically remote cave fish populations that have evolved independently. The phenomenon of varying loss-offunction mutations occurring in the same gene in geographically separate cave populations, but nonetheless causing the same phenotypic effect in them, has also been found for the albino gene as well as for the brown gene (Protas et al., 2007; Gross et al., 2009). In each of these pigment genes, different mutations in separate cave populations cause the same phenotypic defect, namely total or partial loss of melanin. However, although restitution through different mutations in the same gene by recombination is unlikely, it might be likely in case of different mutations in different genes for the eye polygenes.

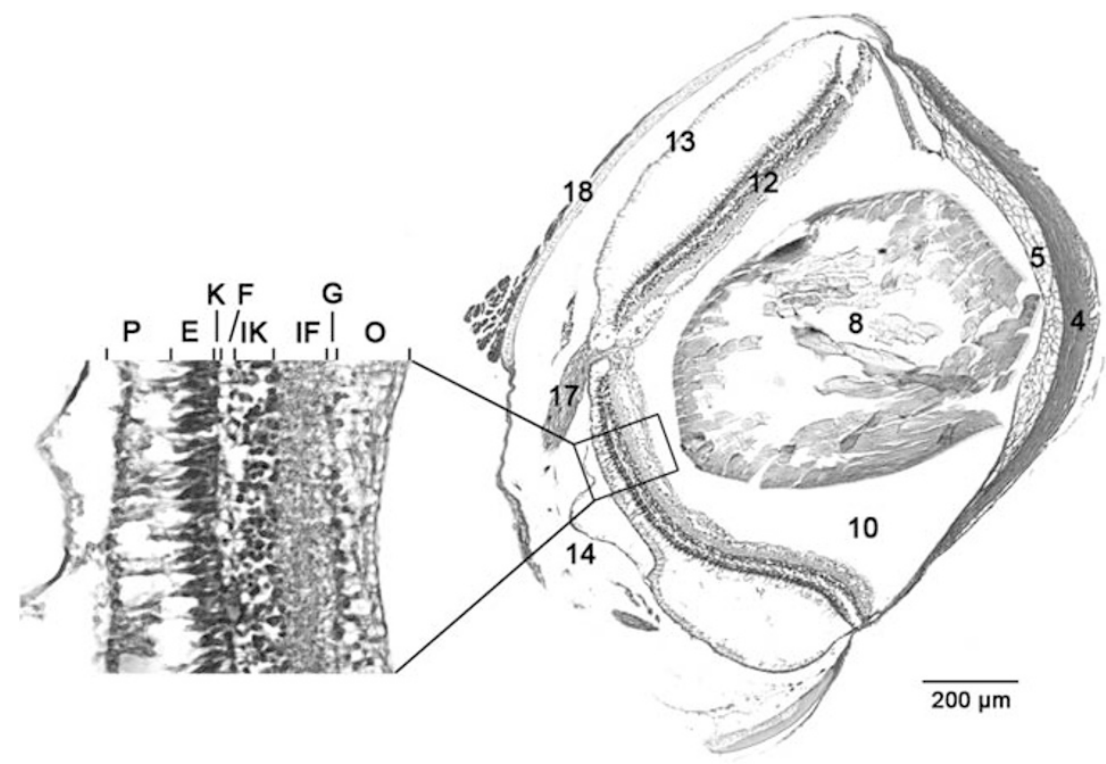

Figure 6 Histological transverse section of the eye of an F2 hybrid specimen ('back to surface eye') between the Pachón and the Molino population (for abbreviations see Figure 4, lens destruction by histological procedure). 
The as yet unidentified genes regulating $h h$ expression are suggested to be equivalent to those genes, which were found by crossing experiments to be responsible for eye size (Wilkens, 1988). They were quantitative in character and were originally called 'eye genes', because it was not possible to identify specific genes, such as ones responsible for the lens or visual cells, with the crossing experiments.

The histological results showing that lens and retinal subunits of the eye are independent, as well as the existence of two subsequent developmental stages of the eye within the cave fish growth curve contributing to eye regression (steps 1 and 2 in Figure 2), suggest that the so-called 'eye genes' divide into two groups: the first group express upstream of the $h h$ genes during the first step of eye regression (Figure 3 , step 1 ). The genes included in the first group would determine the size of the primordial eye cup through regulation of $h \mathrm{~h}$ expression.

However, whereas the size and the degree of differentiation of the lens is determined during the first step of eye development, that of the retina is induced during this first step and additionally during the subsequent second step (Figure 3, step 2). Thus a second group of 'eye genes' is suggested to act during this second step of eye development, regulating structural genes such as those responsible for the visual cell outer segment formation. Hh genes could again be involved as a regulator in the development of the retina, because it is expressed several times during eye development (Amato et al., 2004).

\section{Traits and modules}

Franz-Odendaal and Hall (2006) introduced the term 'module' when referring to different traits, pointing out that in cave fish some modules are lost, such as eye and pigment modules, whereas others are adaptively improved and expanded, such as the taste bud and cranial neuromasts modules. Modules express unique sets of genes with a unique and intrinsic set of developmental patterning mechanisms (Gass and Bolker, 2003; Hall, 2005). The studies of eye genetics in the crossings between cave and surface fish presented here suggest that the eye module relies on a set of structural genes, the eye gene cascade, by the up- or downregulation of which the eye may be enlarged or reduced. Up- or downregulation is suggested to be driven by as yet unidentified genes, which are acting at subsequent ontogenetic stages and regulate the size of the primordial eye cup on the one hand and the differentiation of the retina on the other. As suggested above, these genes seem to be identical to the so-called 'eye genes', which were found to be responsible for eye reduction by crossing experiments.

The analyses of crossing experiments showed, that the phenotypic manifestation of regressive modules such as the eye and of constructive modules such as taste buds, as well as all other modules is identical. From this it could be deduced that the above described findings regarding the eye can principally be conferred on all complex regressive and constructive cave fish modules. Thus, mutations of as yet unidentified regulatory genes would be responsible for the regressive or constructive evolution of a specific module. 'Destructive' mutations of these specific genes would be the ultimate reason for the diminution and final regression of modules such as the eye, just like 'constructive' mutations of such genes would be responsible for the expansion and improvement of constructive modules. Thus, reduction as well as improvement of modules would in principle be based on comparable genetic processes (Wilkens, 2004). In both cases, the mutations occur at random and may be influenced by genetic drift. However, in the cases of constructive evolution selection provides for the direction by eliminating destructive mutations and promoting constructive mutations.

The analyses of F2 hybrids between surface and cave fish did not reveal any phenotypic correlation between the size of the regressive eye and that of cave adaptive traits such as the increased number of taste buds (Schemmel, 1967; Protas et al., 2007), the improved ability of fat storage (Hueppop, 1989), the feeding behaviour (Schemmel, 1980), the aggressive behaviour (Hofmann and Hausberg, 1993) and the enhanced number of teeth (Protas et al., 2007). There was also no significant correlation between the eye size and constructive traits such as the jaw size (Kendall's rank correlation, $\mathrm{Tau}=0.11)$, the larger size of the nose pit $(\mathrm{Tau}=0.019)$ and the broader mouth width $(\mathrm{Tau}=0.027)$. In particular, the size of the eye and the higher number of free neuromasts on the lateral head side of cave fish were not correlated $(\mathrm{Tau}=0.049)$ in the F2 hybrids between cave and surface fish (Wilkens unpublished). This finding is especially remarkable, because the free neuromasts are part of the lateral line sense that allows spatial orientation in darkness by cave fish (Teyke, 1990; Montgomery et al., 2001). Other traits such as the number of melanophores (Wilkens, 1988), number of taste buds and feeding behaviour (Schemmel, 1967, 1980) and improved fat storage (Hueppop, 1989) also were not correlated with eye size. Furthermore, in the eye the special situation of module uncoupling (dioptric vs sensory apparatus) in the sense of Franz-Odendaal and Hall (2006) is found. These observations suggest that different regressive and constructive modules are not correlated and do not show genetic linkage. The independency of modules is suggested to rely on the as yet unknown regulatory genes (= 'eye genes', 'taste bud genes' a. s. o., Wilkens, 1988), which are exclusively responsible for one single module. In contrast to them, the subordinate genes of the module-specific gene cascades (including $h$ h genes) may be expressed in developmental pathways of quite different modules. Thus, a cave fish organism would consist of a set of modules, which evolve independently.

\section{Mechanisms of regression}

\section{Selection}

Recently theories of eye regression, as originally suggested by Barr (1968), have come to the fore again (Niven et al., 2007). According to this theory, eye regression is driven by the same genes, which improve cave adaptive traits such as taste. Eye reduction was therefore hypothesised to be a spin off effect of taste bud improvement (Jeffery, 2005). As a developmental association, the evolution of a series of other cave fish adaptations such as the broader mouth, the increased 
teeth number on the maxillary, the altered feeding behaviour and the larger nose pit were explained, too. However, as described above, studies of F2-crosses between Astyanax surface and cave fish have revealed independent assortment in their inheritance patterns.

The adaptation of the eye of deep sea fish to their light scarce environment provides numerous examples of the advantages of the independent development of modules such as the dioptric and the sensory apparatus. In the pearl eye (Dissoma anale, Scopelarchidae), a huge lens is combined with a small retina whereas in the grid eye (Ipnops murrayi, Ipnopidae) the retina is found stretched over the head and the lens is completely reduced (Munk, 1966). An evolutionary development like this would only be possible if both units are genetically independent. Also the pleiotropic linkage of modules such as those responsible for eye reduction and taste bud number is not necessarily advantageous, but may in a different environment even be an impediment to the evolutionary adaptation process, because it is not necessarily a priori beneficial to improve and reduce specific modules at the same time. It is more probable that two modules do not simultaneously have profitable functions in a new environment. In contrast, the genetic independence of modules provides evolutionary flexibility and should be subjected to strong positive selection.

Protas et al. (2006) found by QTL studies that a number of co-evolved cave-specific traits such as eye size, melanophores, body condition, depth of caudal peduncle or placement of dorsal fin, significantly clustered in the cave fish genome. Although offering several other possible explanations, such as, for example, tight linkage of the QTLs, they favour the hypothesis that 'while not excluding the possibility that some of the QTL clusters have a multigenic basis, the data suggest that a significant portion of the complexity and diversity of the QTL clusters in Astyanax may reflect pleiotropy'.

Another hypothesis suggested is that an exposed eye is a deleterious risk in darkness (Barr, 1968; Strickler et al., 2007). This hypothesis seems unlikely, because cave animals usually derive from troglophile ancestors, which are already adapted to a partial life style in darkness. Such species are mostly night-active and still have small eyes, because selection is acting against the complete loss of eyes. However, they have already improved senses such as taste, olfaction or orientation, which enable them to live in complete darkness, too (Wilkens, 2001).

Energy economy has often been looked on as a driving force of eye reduction. Only recently, it was speculated that the high energetic costs of visual cell metabolism could be a strong selective force in eye regression. This assumption is based on the finding that neural energy costs of fly visual cells do not lower in darkness when kept in a light-dark 12:12 cycle (Niven et al., 2007; Niven, 2008). These results partially concur with findings of retinal protein synthesis in toads (Hollyfield and Anderson, 1982), in which it was found that protein synthesis did not change during the normal light-dark cycle. However, major differences in protein synthesis were evident when animals were stressed with continuous darkness for several days. Under these conditions, a $50 \%$ lowering of retinal protein synthesis, which can be looked on as an indicator of retinal metabolism, took place.
To date, no measurements of energy costs of true cave animal retinas have been taken. As the entire ontogenetic development of cave species takes place in complete darkness and thus proceeds without any light stimulus, one can suspect that this cannot be compared at all with animals kept in a normal light-dark 12:12 cycle even when measured in darkness. This assumption is substantiated by histological analysis of retinas of cave living fish sampled under the exclusion of light in their original habitat. The fish bred in darkness showed considerable destructive malformations of the retina, whereas their offspring, hatched and kept at 12:12 light conditions, developed a completely intact and functional retina (Peters and Peters, 1968; Peters et al., 1975). Therefore, physiological deficiencies caused by retinal destruction can be expected in the original cave fish. To date, it is questionable whether energy economy has a role in cave fish eye reduction.

The hypothesis of energy economy having an important role as a selective factor in eye regression is furthermore improbable, because behavioural traits, the display of which depends on vision, are reduced in the cave fish in darkness. For example, in Astyanax cave fish the visually triggered aggressive behaviour as well as the dorsal light reaction, which are no longer performed when surface fish are kept in darkness, and hence can not be subjected to selection because of energy economy, get reduced in the cave fish, nonetheless (Hofmann and Hausberg, 1993; Langecker, 1993; Hausberg, 1995).

\section{Loss of selection and variability}

Recently, it was found by QTL studies that the pattern of substitution effects between QTL for eye size and melanophore number differed (Protas et al., 2007). In the case of melanophore reduction, this was interpreted as resulting mainly from recurrent mutations with genetic drift, in agreement with the hypothesis that destructive mutations in biological functionless modules are not eliminated by selection. In case of the eyes, Protas et al. (2007) interpreted this difference by the conclusion 'that regression of eyes came about primarily through selection'.

Modules that have lost their biological function do not only get reduced, but are also characterised by genetic and phenotypic variability. This phenomenon is mostly not considered in studies of cave animals although it can usually be found, in particular, in phylogenetically young cave forms in the initial phase of regression (Kosswig, 1940, 1949, 1959; Wilkens, 1988). It can be observed at the individual and population level as well as between populations. In the case of the eye, it is a characteristic that considerable differences in histology and size between the left and the right side eye rudiment of one specimen can usually be observed (Figure 7) (Wilkens, 2001; Wilkens and Strecker, 2003). The eye size of the Micos cave population of Astyanax, which is in the initial phase of eye reduction, ranges between that of the surface fish and an F1-hybrid between surface and strongly reduced cave fish (Wilkens, 1988). The eye size is much greater than that of the more strongly reduced and phylogenetically old cave forms such as Pachón. Furthermore, in cases in which several cave populations have convergently evolved in geographically remote caves, as in Astyanax cave fish or in the Rhamdia cave 


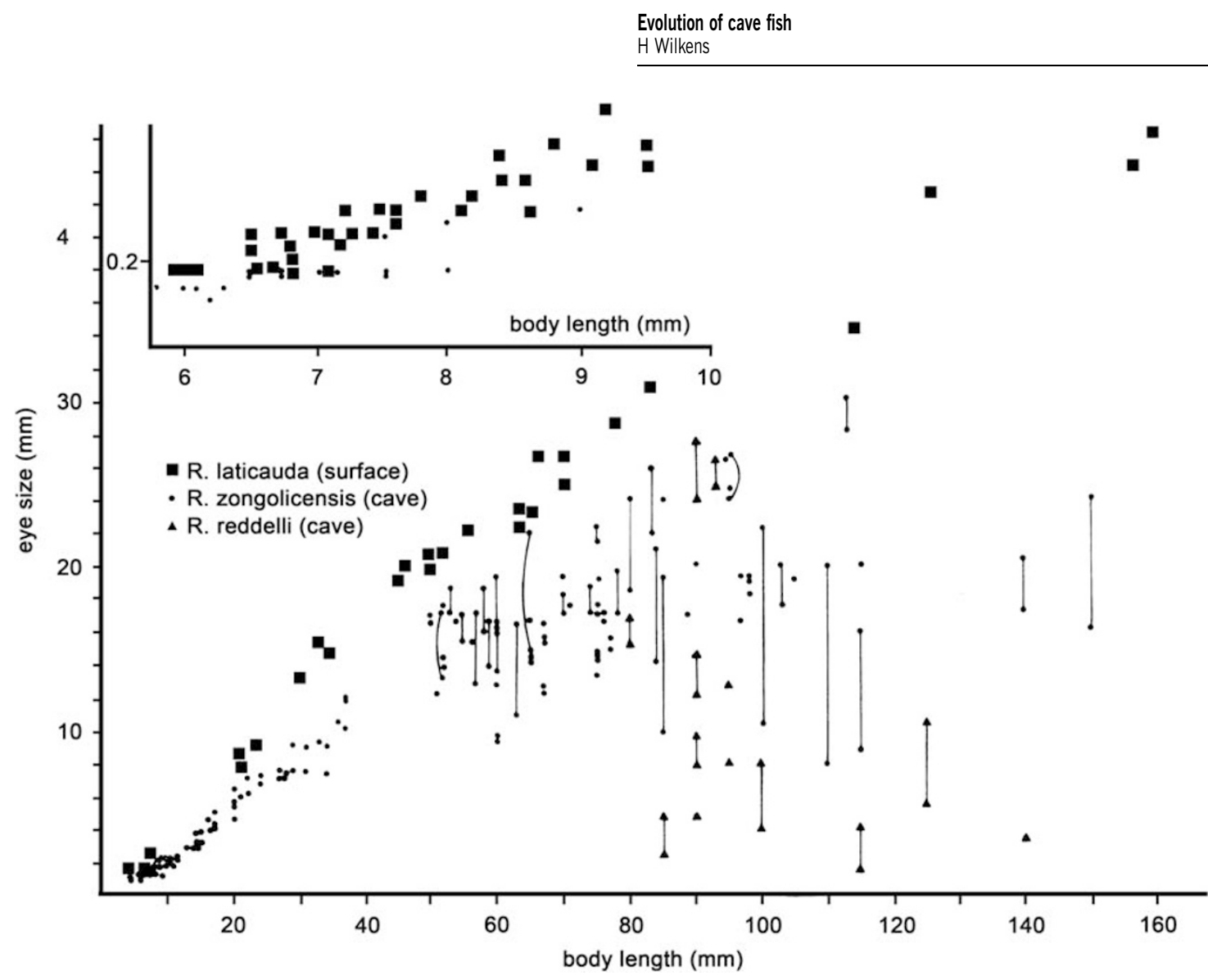

Figure 7 Ontogenetic growth curves of the eyes of the surface catfish Rhamdia laticauda (Pimelodidae) and two of its cave derivatives ( $R$. zongolicensis and $R$. reddelli). Each symbol indicates eye size (measured as eye diameter) and body length (measured as standard length) of one specimen. Connecting lines indicate left-right asymmetry of the eye rudiments found in one single specimen. Insert showing eye growth up to 10-mm body length (from Wilkens, 2001).

catfish (Pimelodidae), genetic as well as phenotypic variability not only occurs within a single cave population, but also between different locally separated cave populations (Culver and Wilkens, 2000; Wilkens, 2001).

I suggest that the variability of regressive traits is attributed to the loss of selection. Explanations of the reduction of biologically functionless traits in cave fish based on selection seem to be less probable because natural selection usually acts strongly to eliminate phenotypic variability. Therefore, variability of regressive traits in cave animals would be one of the rare cases, in which random mutations can manifest and are not eliminated by natural selection acting to preserve the functional capability of a module.

\section{Conflict of interest}

The authors declare no conflict of interest.

\section{Acknowledgements}

I thank Steve Cooper for helpful criticism and improving the English of the paper. Furthermore, I am indebted to Ulrike Strecker and three unknown referees for valuable critical remarks.

\section{References}

Alunni A, Menuet A, Candal E, Pénigault J-P, Jeffery WR, Rétaux S (2007). Developmental mechanisms for retinal degeneration in the blind cave fish Astyanax mexicanus. J Comp Neurol 505: 221-233.

Amato MA, Boy S, Perron M (2004). Hedgehog signalling in vertebrate eye development: a growing puzzle. CMLS, Cell Mol Life Sci 61: 899-910.

Barr TC (1968). Cave Ecology and the Evolution of Troglobites. Evolutionary Biology, Plenum Press: New York. Vol 2, pp 35-102.

Behrens M, Langecker GT, Wilkens H, Schmale H (1997). Comparative analysis of Pax- 6 sequence and expression in the eye development of blind cave fish Astyanax fasciatus and its epigean conspecific. Mol Biol Evol 14: 299-308.

Behrens M, Wilkens H, Schmale H (1998). Cloning of the $\alpha \mathrm{A}$ crystallin genes of a blind cave form and the epigean form of Astyanax fasciatus: a comparative analysis of structure, expression and evolutionary conservation. Gene 216: 319-326.

Culver DC, Wilkens H (2000). Critical review of the relevant theories of the evolution of subterranean animals. In: Wilkens H, Culver DC, Humphreys WF (eds). Ecosystems of the World: Subterranean Ecosystems. Elsevier: Amsterdam. Vol 30, pp 381-398.

Franz-Odendaal TA, Hall BK (2006). Modularity and sense organs in the blind cave fish, Astyanax mexicanus. Evol Dev 8: 94-106.

Gass GL, Bolker JA (2003). Modularity. In: Hall BK, Olson WM (eds). Keywords and Concepts in Evolutionary Developmental Biology. Harvard University Press: Cambridge, pp 260-267. 
Gross JB, Borowsky R, Tabin CJ (2009). A novel role for Mc1r in the parallel evolution of depigmentation in independent populations of the cave fish, Astyanax mexicanus. PLoS Genet 5: e1000326.

Hall BK (2005). Bones and Cartilage. Developmental and Evolutionary Skeletal Biology. Elsevier Academic Press: London.

Hausberg C (1995). Das Aggressionsverhalten von Astyanax fasciatus (Cuvier 1819) Characidae, Teleostei: Ontogenie, Genetik und Evolution bei der epigäischen und hypogäischen Form. MSc Thesis, University of Hamburg.

Hofmann S, Hausberg C (1993). The aggressive behaviour of the Micos cave population (Astyanax fasciatus: Characidae, Teleostei) after selection for functional eyes in comparison to an epigean one. Mémoires de Biospéologie XX: 101-103.

Hollyfield JG, Anderson RE (1982). Retinal protein synthesis in relationship to environmental lighting. Invest Ophthalmol Visual Sci 23: 631-639.

Hueppop K (1989). Genetic analysis of oxygen consumption rate in cave and surface fish of Astyanax fasciatus (Characidae, Pisces). Further support for the neutral mutation theory. Mémoires de Biospéologie XVI: 163-168.

Hueppop K, Wilkens H (1991). Bigger eggs in subterranean Astyanax fasciatus. Z zool Syst Evol 29: 280-288.

Jeffery WR (2001). Cave fish as a model system in evolutionary developmental biology. Dev Biol 231: 1-12.

Jeffery WR (2005). Adaptive evolution of eye degeneration in the blind Mexican cave fish. J Hered 96: 185-196.

Jeffery WR, Strickler AG, Yamamoto Y (2003). To see or not to see: evolution of eye degeneration in Mexican blind cave fish. Integr Comp Biol 43: 531-541.

Kosswig C (1940). Die Variabilität bei Asellus aquaticus, unter besonderer Berücksichtigung der Variabilität in isolierten unter- und oberirdischen Populationen. Fen Fakültesi Mecmuasi 5: 1-55.

Kosswig C (1949). Phänomene der regressiven Evolution im Lichte der Genetik. Communications de la Faculté des Sciences de l'Université d'Ankara 8: 110-150.

Kosswig C (1959). Darwin und die degenerative Evolution. Abhandlungen und Verhandlungen des Naturwissenschaftlichen Vereins in Hamburg IV: 21-42.

Lande R (1981). The minimum number of genes contributing to quantitative variation between and within populations. Genetics 99: 541-553.

Langecker TG (1993). Genetic analysis of the dorsal light reaction in epigean and cave-dwelling Astyanax fasciatus (Teleostei, Characidae). Etho Ecol Evol 3: 357-364.

Langecker TG, Schmale H, Wilkens H (1993). Transcription of the opsin gene in degenerate eyes of cave-dwelling Astyanax fasciatus (Teleostei, Characidae) and of its conspecific epigean ancestor during early ontogeny. Cell Tissue Res 273: 183-192.

Mathers PH, Jamrich M (2000). Regulation of eye formation by the Rx and Pax6 homeobox genes. Cell Mol Life Sci 57: 186-194.

Mitchell RW, Russell WH, Elliott WR (1977). Mexican eyeless characin fishes, genus Astyanax: environment, distribution and evolution. Spec Publ Mus Tex Techn Uni 12: 1-89.

Montgomery JC, Coombs S, Baker CF (2001). The mechanosensory lateral line system of the hypogean form of Astyanax fasciatus. Environ Biol Fish 62: 87-96.

Munk O (1966). Ocular anatomy of some deep-sea teleosts. Dana Report 70: 1-62.

Niven JE (2008). Evolution: convergent eye losses in fishy circumstances. Curr Biol 18: R25-R27.

Niven JE, Anderson JC, Laughlin SB (2007). Fly photoreceptors demonstrate energy-information trade-offs in neural coding. PLoS Biol 5: 828-840.

Peters N, Peters G (1968). Zur genetischen Interpretation morphologischer Gesetzmäßigkeiten der degenerativen Evolution. Z Morph Tiere 62: 211-244.
Peters N, Scholl A, Wilkens H (1975). Der Micos-Fisch, Höhlenfisch in statu nascendi oder Bastard? Z zool Syst Evol 13: $110-124$.

Protas ME, Conrad M, Gross JB, Tabin C, Borowsky R (2007). Regressive evolution in the Mexican cave tetra, Astyanax mexicanus. Curr Biol 17: 452-454.

Protas ME, Hersey C, Kochanek D, Thou Y, Wilkens H, Jeffery WR et al. (2006). Genetic analysis of cave fish reveals molecular convergence in the evolution of albinism. Nat Genet 38: 107-111.

Romero A, Green SM, Lelonek MM, Stropnicky KC (2003). One eye but no vision: cave fish with induced eyes do not respond to light. J Exper Zool 300B: 72-79.

Sadoğlu P (1955). A mendelian gene for albinism in natural cave fish. Experientia 13: 394-395.

Sadoğlu P (1957). Mendelian inheritance in the hybrids between the Mexican blind fishes and their overground ancestor. Verh Dtsch Zool Ges Graz 7: 432-439.

Sadoğlu P, McKee A (1969). A second gene that effects eye and body color in Mexican blind cave fish. J Hered 60: 10-14.

Schemmel C (1967). Vergleichende Untersuchungen an den Hautsinnesorganen ober- und unterirdisch lebender Astyanax-Formen. Ein Beitrag zur evolution der Cavernicolen. Z Morph Tiere 61: 255-316.

Schemmel C (1974). Genetische Untersuchungen zur Evolution des Geschmacksapparates bei cavernicolen Fischen. Z zool Syst Evol 12: 169-215.

Schemmel C (1980). Studies on the genetics of feeding behaviour in the cave fish Astyanax mexicanus f. anopthichthys. An example of apparent monofactorial inheritance by polygenes. Z Tierpsychol 53: 9-22.

Strecker U, Bernatchez L, Wilkens H (2003). Genetic divergence between cave and surface populations of Astyanax in Mexico (Characidae, Teleostei). Mol Ecol 12: 699-710.

Strecker U, Faúndez V, Wilkens H (2004). Phylogeography of surface and cave Astyanax (Teleostei) from Central and North America based on cytochrome b sequence data. Mol Phylogenet Evol 33: 469-481.

Strickler AG, Yamamoto Y, Jeffery WB (2001). Early and late changes in Pax6 expression accompany eye degeneration during cave fish development. Dev Genes Evol 211: 138-144.

Strickler AG, Yamamoto Y, Jeffery WB (2007). The lens controls cell survival in the retina: evidence from the blind cave fish Astyanax. Dev Biol 311: 512-523.

Teyke T (1990). Morphological differences in neuromasts of the blind cave fish Astyanax hubbsi and the sighted river fish Astyanax mexicanus. Brain Behav Evol 35: 23-30.

Wilkens H (1972). Zur phylogenetischen Rückbildung des Auges Cavernicoler: Untersuchungen an Anoptichthys jordani (=Astyanax mexicanus). Annales de Spéléologie 27: 411-432.

Wilkens H (1988). Evolution and genetics of epigean and cave Astyanax fasciatus (Characidae, Pisces). Evol Biol 23: 271-367.

Wilkens H (2001). Convergent adaptations to cave life in the Rhamdia laticauda catfish group (Pimelodidae, Teleostei). Environ Biol Fish 62: 252-261.

Wilkens H (2004). The Astyanax model (Teleostei): neutral mutations and directional selection. Mitt Hamb Zool Mus Inst 101: 123-130.

Wilkens H (2007). Regressive evolution: ontogeny and genetics of cave fish eye rudimentation. Biol J Linnean Soc 92: 287-296.

Wilkens H, Strecker U (2003). Convergent evolution of the cave fish Astyanax (Characidae, Teleostei): genetic evidence from reduced eye size and pigmentation. Biol J Linnean Soc 80: 545-554.

Yamamoto Y, Jeffery WR (2000). Central role for the lens in cave fish eye degeneration. Science 289: 631-633.

Yamamoto Y, Stock DW, Jeffery WR (2004). Hedgehog signalling controls eye degeneration in blind cave fish. Nature 431: 844-847. 